\title{
E pur si muove: tempo e tradução em movimento
}

\author{
Mauricio Mendonça Cardozo*
}

A firmeza, somente na inconstância. (Gregório de Matos)

Ao lado de suas conhecidas figurações de ordem mimética (como imitação, reprodução, representação, transformação, etc.), a tradução encontra também outra variante clássica de figuração, a saber: como uma forma de movimento. Da pitoresca metáfora do trem de carga, de Eugene Nida (1975), ao flerte de Jacques Derrida com a relação entre metáfora, tradução e transporte (Derrida, 2007), é comum - e tão comum ao ponto de nos parecer quase natural - recorrer a variações da noção de movimento (como passagem, transposição, transferência, etc.) para se pensar o que acontece, ou, melhor, o que se passa na tradução.

Nesses casos, a ideia de uma forma concreta de movimento confere força figurativa a um modo de compreender a natureza do fenômeno tradutório - que, em geral, se nos apresenta como algo quase sempre mais abstrato. Ao fazê-lo, porém, essa mesma figura também decreta, de certa maneira, a condenação do fenômeno que representa, na medida em que se funda, a partir daí, uma negatividade irremediável das consequências do deslocamento implícito nessa figuração - suspeito que pela incomensurabilidade entre o movimento de corpos finitos no espaço e o tipo de movimento que tem lugar na tradução, se é que algum movimento tem lugar na tradução. Este é especialmente o caso quando a concepção de movimento em questão se inscreve num universo de limites, digamos, newtonianos, no qual o fenômeno da tradução é reduzido a uma expressão inequívoca do

* Universidade Federal do Paraná. 
movimento (interlinguístico, intercultural, etc.) num mundo de elementos e valores presumidamente concretos, estáveis e uniformes (quando não pretensamente perenes e constantes). Como bem sabemos, instâncias como a da obra original, do sentido do texto, das intenções do autor e das disposições do leitor ideal são elementos frequentemente dimensionados no tom inquebrantável desses termos.

Nesse contexto epistemológico, a tradução sempre move (transporta, transfere), a tradução sempre se move (é efêmera, se esgota, tem prazo de validade), mas é como se assumíssemos que nenhum outro elemento que compõe seu universo mais próximo varia de estado, de condição, de lugar. Nada mais parece dar-se ao movimento, nada mais parece suscetível às movimentações no tempo e no espaço: é como se a posição e a constituição da obra e de seu autor fossem inabaláveis, imutáveis, invariáveis - tudo na conta da preservação de uma condição aurática ou da perpetuação de uma lógica da invariância. É como se a tradução passasse, mas os discursos críticos e os modos de leitura fossem sempre imunes a essa condição de passagem. Enfim, é como se a tradução se inscrevesse sempre na precariedade de um tempo em curso, enquanto o restante do universo se projetaria numa forma de perenidade, na cristalização de uma condição que, apesar de circunstancialmente construída, a força da tradição saberia bem preservar, generalizar e, por fim, naturalizar.

Ora, termos como tradução ou translação - que hoje assinam genericamente nosso objeto de estudo em suas mais diversas variações, em tantas línguas diferentes - já designavam uma forma de movimento em outros contextos, bem antes de nos servirmos desses termos para falar de nossa prática tradutória.

Lembremos, por exemplo, que, na tradição cristã, translação ou transladação é o nome da prática ritualística de transferência de restos mortais ou de objetos sagrados (a chamada translatio das relíquias) de uma localidade para outra. Trata-se de uma prática disseminada por toda a Europa, especialmente durante a Idade Média - notadamente como instrumento de fortalecimento e expansão dos domínios da Igreja Católica -, constituída por uma série pré-definida de etapas que, entre outras, incluíam a inventio, a revelatio e a elevatio, referentes à identificação e à acreditação do objeto a ser 
alçado à condição de relíquia, passando pela translatio, propriamente dita a operação de traslado, que acabaria emprestando seu nome a todo o processo -, até chegar à receptio, ao adventus e à depositio, referentes à recepção e à acomodação da relíquia em seu destino final. Essa prática daria origem, ainda, a uma das expressões importantes da literatura hagiográfica, na forma de narrativas ${ }^{1}$ sobre o processo de transladação; e quando este tinha por objeto as relíquias de um Santo, tais narrativas, não raro, abrangiam também seus feitos miraculosos. Nesse uso ancestral do termo translação, evidencia-se a noção implícita de um movimento que se coloca a serviço da transposição de um objeto, cujo valor presumiremos como invariável. No entanto, são igualmente evidentes tanto a natureza construída desse estatuto sagrado, canônico - seja oficialmente, por meio da inventio, da elevatio ou de processos de canonização, seja extraoficialmente, pelo uso de artifícios que forjam o estatuto de relíquia - quanto o poder fundacional desse movimento translatório - a julgar pelo impacto social, político, econômico e religioso da translatio sobre o contexto de recepção do objeto transladado.

Lembremos, também, que em uma área tão distante do âmbito religioso quanto a geometria, translação designa o movimento que um objeto realiza de um ponto a outro. Em termos um pouco mais técnicos, translação é uma isometria que desloca a figura original segundo uma direção, um sentido e um comprimento. Daí se dizer que a translação seja uma transformação geométrica, em que uma figura é transformada noutra com a mesma forma e dimensão. No campo da geometria, portanto, translação é uma forma de transformação que move objetos - nesse caso, objetos abstratos - sem deformá-los, noção esta que se oferece de modo especialmente sugestivo como representação do fenômeno tradutório, ao menos de um ponto de vista de sua idealidade - resta saber se podemos presumir essa possibilidade ideal como efetiva no campo das práticas discursivas que se inscrevem nos limites da condição humana.

Mas é originalmente do campo da astronomia e da astrofísica que vem um uso do termo translação que nos é, provavelmente, o mais familiar. Translação é um dos movimentos que o planeta Terra realiza: é o movi-

\footnotetext{
${ }^{1}$ Em alemão: Translationsberichte.
} 
mento que a Terra descreve ao redor do Sol e que se completa no período correspondente a um ano.

Aliás, é um alívio poder escrever isso, aqui, sem maiores problemas, uma vez que, hoje, tal afirmação não evoca, senão, uma espécie de lugar comum do discurso e das ciências. Mas sabemos muito bem que a situação nem sempre foi assim. Muitos dos primeiros defensores da teoria heliocêntrica, desenvolvida por Nicolau Copérnico, foram perseguidos pela Igreja Católica e acabaram tendo um destino fatal. Podemos dizer, assim, que, no decorrer do tempo - ao longo dos últimos (quase) cinco séculos -, a própria ideia de translação da Terra (e todo o conjunto de pressupostos heliocêntricos que a sustentam) teria sido objeto de um movimento de tradução, de um contexto marcadamente refratário a essa forma de compreensão do mundo para um contexto em que essa compreensão se coloca como paradigmática e dominante. E se sabemos tão bem que essa tradução do modelo heliocêntrico não se daria sem uma forma radical de transformação - como produto do trabalho incessante de tradução de pensadores, matemáticos e cientistas, como Galieleu Galielei, Johannes Kepler, Isaac Newton, entre tantos outros -, quantas vezes mais marcante não foi a transformação que esses empenhos imprimiram sobre os sujeitos dessas traduções, traduzidos da condição de homem de um mundo clássico para a condição de homem moderno.

Quase três séculos depois de Copérnico ter publicado, em 1543, seu De revolutionibus orbium coelestium, o poeta, escritor e pensador Johann Wolfgang von Goethe, na quarta parte de seu Da teoria das cores, de 1810, escreveria sobre o impacto que a revolução copernicana teve sobre a humanidade da época:

\footnotetext{
Mas entre todas as descobertas e revelações, nenhuma teria um impacto maior sobre o espírito humano do que a teoria de Copérnico. Mal haviam reconhecido que a Terra era redonda e finita em si mesma, e ela já teve de abrir mão do imenso privilégio de ser o centro de todo o universo. Talvez nunca tenham exigido tanto da humanidade; afinal, é preciso levar em conta as coisas todas que esse reconhecimento transformaria em pó e fumaça: a crença em um segundo paraíso, um mundo de inocência, poesia e devoção; a confiança no testemunho dos sentidos, as convicções de uma crença poético-religiosa. Não é de se admirar que a humanidade não te-
} 


\begin{abstract}
nha querido abrir mão tão facilmente de tudo isso; não é de se admirar que a humanidade tenha feito de tudo para se voltar contra essa teoria, que autorizava e impulsionava seus simpatizantes a se servirem de uma grandeza de espírito e de uma liberdade de pensamento até então desconhecida, insuspeitada. (Goethe, 2002, tradução minha)
\end{abstract}

Em 1632, já contabilizando uma passagem pelo Tribunal da Inquisição em 1616, Galileu Galilei publicará uma obra que é sintomática desse forte impacto, na qual se dispõe a debater centralmente as visões geocêntricas e heliocêntricas. Trata-se de seu Dialogo [...] sopra i Due Massimi Sistemi del Mondo, Tolemaico e Copernicano (Galilei, 2002)², em que Galileu dá voz a três personagens: Salviati (que defende o heliocentrismo copernicano), Simplício (um indivíduo teimoso e atoleimado, que defende o geocentrismo ptolomaico-aristotélico) e Sagredo (figura aparentemente neutra, mas que acaba por simpatizar com Salviati).

Não é demasiado lembrar, aqui, que a publicação desse Diálogo de Galileu teria sido a gota d'água para o desenlace de um novo processo a que o submeteria o Tribunal da Inquisição, que o acabaria condenando à prisão domiciliar, censurando suas obras e obrigando-o a abjurar suas ideias. Reza a lenda, perpetuada por biógrafos - mas, vale observar, igualmente desmentida por outros especialistas -, que, encerradas as sessões do tribunal, Galileu, a meio caminho entre resignado e indignado, teria proferido a famosa frase: E pur si muove. Ou seja, digam o que quiser, façam-me dizer o que for, mas, que se move, se move - referindo-se, então, à ideia de que a Terra, ao invés de um ponto fixo no centro do universo, estaria em movimento (pressuposto fundamental da virada heliocêntrica).

A repercussão dessa obra de Galileu, especialmente em países protestantes, como a Holanda, que não se sujeitava aos vetos católicos, impulsionou o debate em torno da proposta heliocêntrica, cujo modelo, ao longo dos anos que se seguiram à publicação do Diálogo, seria continuamente aprimorado. Desde então, uma legião de filósofos, teólogos, físicos, astrônomos e epistemólogos vêm se ocupando dessas ideias (como uma forma

\footnotetext{
2 Em português: Diálogo [...] sobre os dois principais sistemas do mundo, ptolomaico e copernicano. Para os fins deste artigo, tomo por base a tradução alemã (Dialog über die Weltsysteme) de Emil Strauss (1891), revisada por Ferdinand Fellmann e editada pela Suhrkamp. As traduções que se seguem são todas minhas, a partir da referida edição alemã.
} 
incessante de tradução da obra de Copérnico), bem como das demais contribuições de Galileu. Revolução copernicana é uma expressão que não tardaria a entrar na ordem do dia em diversas áreas, em diversas épocas, em diversas línguas. E o fato de que foi com essa expressão que, no final do século XVIII, o filósofo Immanuel Kant, no prefácio à segunda edição de sua primeira Crítica, sintetizou o sentido mais amplo do trabalho que empreendera em sua obra, pode nos dar uma impressão razoável da relevância do legado copernicano.

Valeria a pena lembrar aqui, ainda, da expressão que esse grande debate cosmológico encontraria na literatura, instalando-se, de um modo ou de outro, na longa tradição do topos da máquina do mundo, de Dante e Camões à Drummond e Haroldo de Campos, cada qual tendo por pano de fundo as convicções e os dilemas próprios de seu tempo. E é também a essa discussão das ordens celestes que aludem os três anjos no prólogo ${ }^{3}$ que abre o (primeiro) Fausto, de Goethe (2005). Já Giacomo Leopardi, em seu diálogo Il Copernico (Leopardi, 1827), colocará o astrônomo polonês para conversar com o próprio sol, que, por sinal, ao receber sua visita, não se presta a convidar Copérnico nem mesmo para se sentar. Por sua vez, a peça A vida de Galileu4, de Bertolt Brecht (1998), acabará se transformando numa das obras mais importantes do dramaturgo alemão, atualizando, para o século $X X$, algumas das problemáticas da relação entre ciência, religião e sociedade - em especial no que diz respeito à questão do dogmatismo.

À época de sua publicação, o diálogo de Galileu conquistou a atenção (e o ódio) de muitos de seus leitores, especialmente em razão do modo singular com que o autor argumenta sobre os movimentos de rotação e translação da Terra no horizonte de uma visão heliocêntrica. Hoje, aos olhos de um leitor contemporâneo - leigo ou especializado -, nem as questões de fundo, tampouco os argumentos centrais de Galileu são capazes de evocar uma reação comparável. Quando muito, sensibilizamo-nos diante do valor histórico do debate.

No entanto, ao acompanharmos o movimento descrito por essa obra no curso dos quase quatro séculos que nos separam de sua publicação, ou-

\footnotetext{
${ }^{3}$ Em alemão: Prolog im Himmel (Prólogo no céu).

${ }^{4}$ Em alemão: Das Leben des Galilei.
} 
tra questão - originalmente de caráter subsidiário - parece vir à tona e assumir mais evidentemente o primeiro plano do debate. Trata-se de uma questão que, como forma de contraponto às discussões mais centrais para aquela época, acompanha os quatro dias de debate que compõem e estruturam o diálogo, apresentando-se logo no prólogo.

Nesse texto de abertura e apresentação (Galilei, 2002, p.136-139), o autor afirma que o propósito de seu diálogo não é o de provar a superioridade de nenhum dos dois sistemas (a saber, o copernicano, heliocêntrico, em relação ao ptolomaico, aquele que pressupunha a imobilidade da Terra), mas, sim, o de discutir detalhadamente os argumentos que sustentam cada um dos modelos (p.137) - se essa posição, aos olhos daquela época, pode ser entendida como representativa de uma estratégia de defesa ante os previsíveis ataques da Inquisção, hoje ela nos chama a atenção, também, pelo que representa enquanto desenho de um pensamento atento, minucioso e crítico, que (cum grano salis) bem poderia aproximar o pensador Galileu de muitos autores contemporâneos. Galileu justifica sua iniciativa por entender que os autoproclamados peripatéticos (nesse contexto, os aristotélicos defensores do geocentrismo) se arrogavam o direito de usar esse nome, mas, sem serem eles mesmos "pensadores em movimento" (p.137), não faziam mais que venerar meros fantasmas. Em outras palavras, logo no prólogo desse livro publicado em 1632, à medida que os chamados peripatéticos são caracterizados pela imobilidade de seu pensamento - o que evidencia, sardonicamente, um descompasso em relação à rubrica que os designa -, delineia-se essa outra questão que atravessa todo o Diálogo: o dogmatismo.

No primeiro dia de debate (p.145), na voz de Salviati, o próprio Aristóteles surge caracterizado como alguém que estaria mais interessado em alcançar os objetivos que estabelecera previamente, do que em se deixar levar livremente na direção para a qual apontavam suas admiráveis reflexões. Ou seja, o pensamento de Aristóteles é em grande medida preservado como digno de admiração, mas o homem Aristóteles é colocado sob suspeição. Galileu acusa o homem Aristóteles de não ter sido capaz de levar seu próprio pensamento às últimas consequências. 
Mais adiante, em réplica a Simplício, que exige mais respeito diante da figura do "inesgotavelmente admirável perscrutador das figuras silogísticas [...], enfim, o pai da lógica" (p.152), Salviati explica-lhe que não se trata de uma forma de desrespeito, e rebate:

\begin{abstract}
A lógica é, como o Senhor bem sabe, o instrumento da filosofia. E do mesmo modo como alguém pode ser um grande fabricante de instrumentos sem saber tocá-los muito bem, é possível tornar-se um grande conhecedor da lógica, sem necessariamente saber usá-la com excelência. Assim como também há muitas pessoas que sabem dizer de cor as regras todas da poética, sem sequer conseguir escrever uma quadra. [...] Aprendemos a tocar um instrumento com aqueles que sabem tocá-lo como ninguém, não com aqueles que sabem como construí-lo (p.153).
\end{abstract}

De novo, o pensamento do grande peripatético é, em grande medida, preservado; já a exemplaridade da figura de Aristóteles é colocada em questão.

Mas entre tantas passagens semelhantes ao longo do diálogo - que, juntas, constroem um contraponto dogmático a toda a discussão -, uma delas, logo no início do segundo dia de debate, merece aqui destaque por sua força de evidência. Agora, é a voz de Sagredo que se faz ouvir:

\begin{abstract}
Certo dia, estava na casa de um médico muito respeitado de Veneza, para onde costumavam se dirigir muitas pessoas, alguns em razão de seus estudos, outros pela simples curiosidade de ver a dissecação de um cadáver ser realizada pela mão de alguém que era tanto um exímio especialista de sua área quanto um habilíssimo e cuidadoso anatomista. Naquele dia, tratava-se de se examinar a origem e as ramificações do sistema nervoso, o que calhava ser também o tema de uma famosa querela entre os médicos da escola de Galeno e os peripatéticos. (p.160)
\end{abstract}

Segundo a sequência da exposição de Sagredo, o anatomista mostra então, em detalhes, como os nervos todos partiam do cérebro em grandes feixes, descendo pela medula espinhal e dispersando-se em pequenas ramificações por todas as partes do corpo, até chegar ao coração. Encerrada a demonstração, o médico vira-se para um senhor muito distinto, que ele sabia ser um peripatético, e pergunta-lhe, com todo cuidado e respeito que a situação prescrevia, se ele estaria satisfeito e convencido de que os nervos, afinal, teriam sua origem no cérebro, e não no coração. Diante da pergunta, 
depois de refletir por um instante, o filósofo lhe responde: “O Senhor me mostrou tudo de modo tão claro e tão inequívoco - não fosse pelo texto de Aristóteles, que diz justamente o contrário, que a origem dos nervos é o coração, e eu me veria forçado a concordar que o Senhor tem razão" (p.160).

Nessa passagem, os peripatéticos são emblematicamente caracterizados como ouvintes de vontades endurecidas, como aqueles a que Antônio Vieira se refere e compara às pedras, em seu Sermão da Sexagésima (Vieira, 2003, p.34-35) - texto escrito, por sinal, apenas cerca de vinte anos depois do diálogo de Galileu. Não há argumento, não há evidência, não há pensamento capaz de abalar, de mover, de transformar o modo de pensar desses defensores não de Aristóteles, mas de um modo imobilizado, de um modo dogmático de se servir de Aristóteles como um instrumento de autoridade. Na época de Galileu, ganha corpo um novo modo de ler o mundo, um novo modo de pensar o mundo; mas a tradição ancestral dominante parece insistir numa forma de resistência a qualquer mudança, à revelia das argumentações. E é decisivo lembrar que é sobre essa mesma base inabalável e intransigente que se sustentará um poder laico e eclesiástico, em nome do qual tantas guerras serão travadas e tanta gente será condenada à morte.

E pur si muove... poderíamos dizer aqui também, agora numa variação transladada, de quem lê esse diálogo e pensa nessa famosa expressão quatro séculos mais tarde. E diante desse movimento de tradução para a perspectiva de um outro tempo, e pur si muove ganha um sentido adicional: o que se move, agora, não é apenas a Terra. A mobilidade em jogo é a de nós mesmos e a de nossas ideias, é a mobilidade da mentalidade dos doutos, do público e das instituições, é a mobilidade da forma de pensar e de replicar o pensamento. $\mathrm{O}$ que num tempo leva o homem à fogueira, noutros tempos faz a sua fortuna. No entanto, se move. A expressão significa, agora, que nos movemos, que nossas convicções, verdades, crenças e teorias se movem, se transformam, se reescrevem, se traduzem no curso do tempo e nos dão, assim, uma medida da transformação de nosso mundo e de nós mesmos. 
Trata-se de flagrar aqui, nesse Galileu transladado, nesse movimento de leitura e releitura (nesse sentido mais amplo, portanto, de tradução) do diálogo de Galileu, a transformação dos próprios sujeitos do movimento, que, na exata medida de sua mobilidade ao longo dos séculos, foram capazes de transformar os limites do mundo em que habitam. Vale destacar que esse movimento não consiste simplesmente em transgredir os limites do mundo, mas, sim, em assumir que o modo como nos permitimos ver o mundo contribui decisivamente para o estabelecimento e reestabelecimento desses limites.

Lembrando da discussão que o comparatista Naoki Sakai ${ }^{5}$ vem fazendo nos últimos anos a propósito da relação entre as noções de tradução e de fronteira, insistindo na ideia de que a tradução não é simplesmente um movimento que transpõe fronteiras (pré-existentes na forma substantiva da expressão borders), mas, também, o movimento responsável por estabelecêlas (quando a fronteira se verbaliza no próprio ato da tradução, como uma forma de bordering), trata-se aqui de pensar, com Galileu, que, na condição de tradutores e pesquisadores da tradução, mas também como seres humanos em geral, somos, em grande medida, os criadores de nossas próprias imobilidades. E pur si muove...

\section{Referências}

BRECHT, Bertolt. Das Leben des Galilei. Frankfurt: Suhrkamp, 1998.

DERRIDA, Jacques. The Retrait of Metaphor, traduzido para o inglês por Peggy Kamuf. In: Psyche: Inventions of the Other, vol. 1. Stanford, Califórnia: Stanford University Press, 2007, p.48-80. [publicado originalmente em francês, na edição de número 7 da revista Poesie, em 1978]

GALILEI, Galileu. Dialog über die Weltsysteme, tradução de Emil Strauss, revista por Ferdinand Fellmann. In: Sidereus Nuncius. Nachricht von neuen Sternen. Frankfurt: Suhrkamp, 2002, p. 133-230

GOETHE, Johann Wolfgang von. Zur Farbenlehre. In: Goethes Werke [Hamburger Ausgabe], vol. 14. Munique: Verlag C. H. Beck, 2002, p.81.

\footnotetext{
${ }^{5}$ A exemplo do que, entre outros trabalhos, o autor apresenta em sua conferência "Translation and the Schematism of Bordering" (Sakai, 2009).
} 
Faust. Frankfurt: Deutscher Klassiker Verlag, 2005, p. 25

LEOPARDI, Giacomo. Il Copernico, 1827. In:

http://www.leopardi.it/operette_morali21.php Acessado em 27.09.2015.

NIDA, Eugene. Language Structure and Translation: Essays by Eugene A.

Nida. Stanford, Califórnia: Stanford University Press, 1975.

SAKAI, Naoki. Translation and the Schematism of Bordering. Manuscrito apresentado no encontro Gesellschaft Übersetzen: Eine Komentatorenkonferenz. Universidade de Constança, 2009. In: http://www.translatingsociety.de/conference/papers/2/. Acessado em 29.09.2015.

VIEIRA, P. Antonio. Sermão da Sexagésima. In: Sermões, organizado por Alcir Pécora. São Paulo: Hedra, 2003, p. 27-54.

Resumo: A partir da leitura do famoso diálogo de Galileu Galilei sobre os sistemas ptolomaico e copernicano e do destaque, neste, da questão subsidiária do dogmatismo, este ensaio tem por objetivo discutir a força transformadora de nossas leituras e releituras, apontando como a mobilidade do pensamento, qual um movimento de tradução no curso do tempo, exerce impacto sobre a construção do modo como entendemos os limites de nosso próprio mundo.

\begin{abstract}
Through the reading of the famous Galileo Galilei dialogue on Ptolemaic and Copernican systems and by highlighting the subsidiary issue of dogmatism in it, this essay aims to discuss the transforming power of readings and rereadings. It hopes to draw attention to the way in which mobility of thought, like the movement of translation over the course of time, affects the construction of the way the limits of one's own world are understood.
\end{abstract}

